\title{
The Impact of the COVID-19 Epidemic on Diagnosis, Treatment, Concerns, Problems, and Mental Health in Patients with Gastric Cancer
}

\author{
Fatemeh Baghernezhad Hesary ${ }^{1}$ Hamid Salehiniya ${ }^{2}$
}

Accepted: 17 August 2021 / Published online: 14 September 2021

๑) Springer Science+Business Media, LLC, part of Springer Nature 2021

\begin{abstract}
Introduction COVID-19 epidemic has had different effects on many diseases, including gastric cancer. Due to COVID-19 epidemic the importance of knowing the effects of the epidemic in patients to deal with it, the present study aimed to investigate the effect of COVID-19 on the diagnosis, treatment, concerns, problems, and mental health of patients with gastric cancer.

Methods The present study was a systematic review by searching the PubMed, Scopus, and Web of Science databases with the keywords of COVID-19 and gastric cancer. The articles that addressed any aspect of COVID-19 epidemic on diagnosis, treatment, problems, and mental health in patients with gastric cancer were included; the data were qualitatively summarized and presented in related tables.

Results A total 22 articles were included. The effects of COVID-19 on gastric cancer were divided into four categories of the effects of COVID-19 on the diagnosis, treatment and follow-up, concerns, and problems and mental health of patients with gastric cancer. The COVID-19 epidemic has reduced the number of screenings, altered treatment, and delayed or discontinued treatment, which caused problems and concerns such as sleep disturbances and stress.

Conclusion Considering the effects of COVID-19 epidemic on gastric cancer and on the other hand, the continuation of the epidemic in the society, it is necessary for the officials and experts of the health system to design and implement necessary interventions to minimize the negative effects of epidemic on patients with gastric cancer.
\end{abstract}

Keywords COVID-19 · Diagnosis · Treatment $\cdot$ Mental Health $\cdot$ Gastric cancer $\cdot$ Systematic review

\section{Introduction}

In late 2019, a type of pneumonia caused by coronavirus 19 was recognized as a global epidemic with a significant impact on global health [1]. This pandemic caused the death of more than one million people also caused many people suffering and disruption in their lives [2]. Protective behaviors and personal hygiene are effective in preventing the spread of the disease [3]. The COVID-19 epidemic has had a rapid and large impact on the health care system worldwide [4]. Reduction in health care has a great impact on diagnosis

Hamid Salehiniya

alesaleh70@yahoo.com

1 Department of Public Health, Ghayen School of Nursing and Midwifery, Birjand University of Medical Sciences, Birjand, Iran

2 Social Determinants of Health Research Center, Birjand University of Medical Sciences, Birjand, Iran and treatment on patients who had serious illnesses such as cancers [5].

Cancer is one of the leading causes of death in the world [6]. Increased life expectancy and aging of the population are the causes of cancer in communities [7]. Various factors such as screening rate, environmental factors, and socioeconomic status of communities affect the incidence and mortality of cancer [8]. Among cancers, gastric cancer is the most common type of upper gastrointestinal cancers and third leading cause of death in cancer in both sexes. Gastric cancer is usually diagnosed in the late stages, so it needs more careful attention to obtain early diagnosis [9].

Services to cancer patients have declined following the outbreak of the COVID-19 [10], Lack of medical services such as endoscopy services and cancer diagnosis is one of the problems of COVID-19 epidemic in the treatment of patients with cancers in the UK [5]. In order to reduce the transmission of contamination and saving resources on outpatient visits, avoidable hospitalizations were reduced, 
which has disrupted the diagnosis and treatment of patients with gastric cancer [1]. According to the COVID-19 epidemic, delay in treatment is expected to lead to some complications [11]. Metastasis, deterioration of the patient's nutritional status [12], upper gastrointestinal bleeding, and increasing surgical complications are due to delayed treatment [11]. Restrictions caused by the epidemic have a negative impact on people's emotions psychologically and physiologically [13]. It is not yet obvious how long the epidemic and restrictions will continue [5], On the other hand, gastric cancer is one of the most common cancers in the world [9]; therefore, evaluating the effects of COVID-19 on cancer should consider as main issue, and health professionals should be prepared to deal with the long-term effects of COVID-19 as soon as possible [7]. Due to the different effects of the COVID-19 epidemic on patients and the lack of an appropriate comprehensive study in this regard, the present article aimed to investigate the impact of the COVID-19 epidemic on the diagnosis, treatment, concerns, problems, and mental health of patients with gastric cancer.

\section{Methods}

\section{Search Strategy}

A comprehensive search was conducted on 2021 in Medline, Web of science, and Scopus. Keywords such as COVID-19, COVID 19 Pandemic, Coronavirus Disease 2019, Infection, SARS-CoV-2, COVID-19 Virus Infections, SARS Coronavirus 2 Infection, Stomach Neoplasms, Neoplasm, Stomach, Stomach Neoplasm, Gastric Neoplasms, Gastric Neoplasm, Cancer of Stomach, Stomach Cancers, Gastric Cancer, Cancer, Gastric, and Stomach Cancer were used for the search, as single or in combination.

\section{Screening and Eligibility}

The search results were entered into the Endonote-X8 software, which automatically removes duplicate articles. Then, the title and the abstract and finally, the complete text of the articles were studied. Next, full-text articles were reviewed to confirm eligibility criteria; at the end, articles that addressed the effect of COVID-19 epidemic on diagnosis, treatment, concerns, and problems and mental health of patients with gastric cancer were included in the review.

\section{Inclusion Criteria}

Observational studies conducted throughout the world, published English language, and addressing the effect of COVID-19 epidemic on diagnosis, treatment, concerns and problems and mental health of gastric cancer patients were included in the review.

\section{Exclusion Criteria}

Review studies, case reports, letters to editor (not research letter), and clinical trial study articles were excluded from the review.

\section{Data Extraction}

Information about each article including author name, country, type of study, and main result were extracted and entered in pre-designed tables.

\section{Quality Assessment}

The Newcastle-Ottawa Quality Assessment Form was used to assess the quality of articles included in the review; this tool contains 3 separate sections: selection, comparison, and result. Studies scored based on the overall scores and divided into 3 categories: Good, Fair, and Poor [14].

\section{Results}

Selection of Studies In the initial search, 187 articles were found, of which 53 articles were deleted due to duplication, 134 articles were reviewed in terms of title and abstract, which 112 articles were deleted due to lack of relevance, then the next step is full text stage, of which 22 articles were related to the objectives and their results were extracted qualitatively presented in tables (Fig. 1).

\section{Study Characteristics}

A total of 22 studies were eligible for the study according to the objectives of the study and were divided into four categories. The effect of COVID-19 epidemic on the diagnosis of gastric cancer [2, 4, 5, 15-19], treatment and follow-up [1, 20-23], problems and concerns of patients with gastric cancer $[20,21,24,25]$, and health psychiatry of patients with gastric cancer $[1,25,26]$.

\section{Gastric Cancer Screening and Diagnosis}

During the COVID-19 epidemic, the number of screenings for gastric cancer has been decreased [2, 4, 5, 15-19, 27]. In Italy, the number of endoscopies has decreased by $53.6 \%$ compared to 2019 [19]. In the Netherlands, the rate of gastroscopy has decreased by $57 \%$. The number of endoscopies depends on the duration and severity of the restrictions associated with COVID-19 [5]. On the other hand, at the 
time of the COVID-19 epidemic, referrals and diagnosis of endoscopic function had improved compared to before, and inappropriate endoscopic referrals had decreased by 2020 . Due to the constant availability of gastric cancer diagnostic services before and after the COVID-19 epidemic, patients "and physicians" attitudes toward the risk of COVID-19 can be one of the reasons for the endoscopy performance decline [19]. There is a linear model relationship between the number of endoscopies and gastric cancer [18]. The number of endoscopies decreased during the COVID-19 epidemic, but the rate of diagnosis increased significantly [16].

The effect of COVID-19 epidemic on the diagnosis of gastric cancer is summarized in Table 1

\section{Treatment and Follow-Up of Gastric Cancer}

The COVID-19 pandemic led to changes in treatment and patient visits. Some patients have received telephone

Table 1 The effect of COVID-19 on the diagnosis of gastric cancer

\begin{tabular}{|c|c|c|c|c|}
\hline First author & Country & Study design or source of the data & Quality & Main result \\
\hline Buscarini [4] & Italy & Web based survey & Good & $\begin{array}{l}\text { Compared to } 2019, \text { in } 2020 \text {, the diagnosis of } \\
\text { patients with gastric cancer decreased by } 15.9 \% \\
\text { due to the decrease in the volume of diagnostic } \\
\text { services }\end{array}$ \\
\hline De Vincentiis [15] & Italy & & Fair & $\begin{array}{l}\text { The diagnosis of gastric cancer in } 2020 \text { has } \\
\text { decreased by } 10 \% \text { compared to } 2018 \text { and } 2019\end{array}$ \\
\hline Wheaton [5] & The UK & Retrospective study & Fair & $\begin{array}{l}\text { During the COVID- } 19 \text { epidemic, the endoscopic } \\
\text { volume decreased by } 88 \% \text { and cancer diagnosis } \\
\text { rate decreased by } 66 \% \text {. This reduction depends } \\
\text { on the duration and severity of the restrictions }\end{array}$ \\
\hline Brito [2] & Portugal & Retrospective study & Good & $\begin{array}{l}\text { In } 2020 \text {, most patients were referred from the } \\
\text { emergency department, indicating a delay in } \\
\text { requesting clinical attention }\end{array}$ \\
\hline Manes [19] & Italy & Retrospective study & Fair & $\begin{array}{l}\text { The number of rapid endoscopic procedures has } \\
\text { decreased by } 53.6 \% \text { compared to } 2019 \text { and } 2020 \\
\text { One of the reasons for this decrease was the } \\
\text { perception of patients and physicians of the risk } \\
\text { of COVID-19 }\end{array}$ \\
\hline Lantinga [17] & Netherlands & Retrospectively analyzed endoscopies & Good & $\begin{array}{l}\text { By } 2020 \text {, endoscopy has declined, which gas- } \\
\text { troscopy has decreased by } 57 \% \text {. During corona } \\
\text { virus limitations, the diagnosis of cancer has } \\
\text { been significantly reduced. But after lifting } \\
\text { the restrictions, the endoscopy performance } \\
\text { returned to normal } \\
\text { The endoscopies were postponed or canceled }\end{array}$ \\
\hline Lui [18] & China & A population-based study & Good & $\begin{array}{l}\text { The average number of stomach cancers diag- } \\
\text { nosed each week decreased by } 46.2 \% \\
\text { The results of linear regression model showed that } \\
\text { there is a relationship between the number of } \\
\text { gastric cancers and endoscopy performing }\end{array}$ \\
\hline Huang [16] & China & A retrospective cohort study & Good & $\begin{array}{l}\text { Endoscopy decreased by } 30.63 \% \text { during the } \\
\text { epidemic compared to the same period last } \\
\text { year. The rate of gastric cancer diagnosed has } \\
\text { increased in endoscopies }\end{array}$ \\
\hline Armellini [28] & Italy & Retrospectively analyzed endoscopies & Good & $\begin{array}{l}\text { In the study of } 847 \text { patients from } 13 \text { centers in } \\
\text { Italy for endoscopy. } 29.4 \% \text { of patients did not } \\
\text { have an endoscopy due to fear of becoming } \\
\text { infected with COVID-19 virus }\end{array}$ \\
\hline Cai [12] & China & Retrospectively study & Good & $\begin{array}{l}\text { The results showed that } 2 \text { months delay leads to } \\
\text { advanced lymph node metastasis and deterio- } \\
\text { ration of the patient's nutritional status and is } \\
\text { effective in disease mortality }\end{array}$ \\
\hline Giuliani [29] & Italy & Retrospective analysis & Good & $\begin{array}{l}\text { The results of a study on } 29 \text { patients showed a } \\
14.5 \% \text { reduction in diagnostic tests. A } 76 \% \\
\text { decline in the registration of new patients was } \\
\text { observed during the restriction time }\end{array}$ \\
\hline
\end{tabular}


or video counseling instead of going to the hospital [21]. Referrals have decreased by $12 \%$ compared to 2019 . Also, patient revisiting has decreased [23]. Deviation and change of treatment are also among the effects of COVID-19 on gastric cancer, which include adjusting, delaying, and discontinuing treatment. Furthermore, the treatment process changed for $20 \%$ of patients. Delay and discontinuation of treatment mainly include chemotherapy, and immunotherapy has been observed [21]. In addition, outpatient consultations, admission of hospitalized patients, the performance of the chemotherapy, and surgeries have decreased [20]. Patients' treatment switched from intravenous to home treatment was other change. A total of $89.2 \%$ of patients with gastric cancer reported receiving at least one supplement or alternative

Table 2 The effect of COVID-19 on the treatment and follow-up of gastric cancer

Quality Main result

assessment

de Joode [21]

Netherland

Patients' perspective

Good

Zhang [1]

China

A cross-sectional study

Good

Wahed [23]

United king dam A surgical perspective

Fair

Akhtar [20]

India

Retrospective cohort study

Good

Takahari [22]

Japan

Experience in The Cancer Institute Hospital

Fair

Erdem [13]

Turkey

Prospective cross-sectional study

Good

Aznab [31] Iran
Retrospectively study
Most clients received telephone or video counseling instead of going to the hospital

Treatment was delayed in $12 \%$ of treated patients

In $20 \%$ of treated patients, the patient's treatment changed. In modified patients, $30 \%$ were chemotherapy and $32 \%$ were immunotherapy

A total of $60.3 \%$ of patients have received at least one type of supplement or alternative medicine

Most patients switch from intravenous therapy to oral therapy at home

A total of $89.2 \%$ of gastric cancer patients began to seek complementary therapies

Compared to 2019, the number of referrals has decreased by $12 \%$

Revisiting of patients was also reduced

The number of new patients decreased

In 2020, outpatient counseling, patient admission, and chemotherapy unit performance decreased by $62 \%, 58 \%$, and $56 \%$, respectively, compared to the same period of the previous year

In the treatment of cancer, major surgery was reduced by $31 \%$ and cosmetic surgery by $45 \%$

Admission and physical therapy have decreased by more than $50 \%$

Due to the severity of the COVID-19 epidemic and the presence of risk factors such as age over 75 years, comorbidities such as hypertension, diabetes, lung, kidney and liver problems, it is recommended to change the treatment

During the study on 300 patients, receiving medical services was difficult due to the risk of infection, some on the advice of a doctor, some due to fear of delay in receiving treatment. $71.3 \%$ of patients started taking the supplement with their decision

In 279 evaluated patients with cancer were during a 90-day period. The patients were treated according to protective principles and none of them became infected 
Table 3 Concerns and problems of gastric cancer patients during the COVID 19 epidemic

\begin{tabular}{|c|c|c|c|c|}
\hline First author & Country & Study design/source of the data & Quality & Main result \\
\hline de Joode [21] & Netherland & Patients' perspective & Good & $\begin{array}{l}\text { Many patients were concerned about the consequences of the } \\
\text { COVID-19 epidemic on treatment or follow-up } \\
\text { Among patients with delayed and discontinued treatment, } \\
55 \% \text { and } 62 \% \text { were concerned, respectively } \\
\text { A total of } 47 \% \text { of respondents were very worried about get- } \\
\text { ting a COVID-19 infection. Patients who were treated were } \\
\text { much more concerned than patients who were followed up }\end{array}$ \\
\hline Chia [24] & Singapore & Qualitative study & Good & $\begin{array}{l}\text { There was a strong sense of threat in COVID 19, vulner- } \\
\text { ability, and fear of patients' feelings during the COVID-19 } \\
\text { epidemic }\end{array}$ \\
\hline Akhtar [20] & India & retrospective cohort study & Good & $\begin{array}{l}\text { Problems faced by patients included transportation, percep- } \\
\text { tion of infection risk and financial issues, lack of social } \\
\text { support. Meals have been prepared during the trip }\end{array}$ \\
\hline Pigozzi [25] & Italy & Prospective study & Good & $\begin{array}{l}\text { A total of } 53 \% \text { of patients felt highly vulnerable, } 16 \% \text { feeling } \\
\text { confused, } \\
\text { Patients' sense of pleasure and interest also decreased during } \\
\text { the corona epidemic } \\
\text { Sadness and discomfort, and sleep problems were other } \\
\text { problems that increased during the corona epidemic }\end{array}$ \\
\hline
\end{tabular}

medicine, and only $25.9 \%$ of patients talked about complementary and alternative therapy with their physician or nurse. Most people start complementary therapy on their own and are unaware of its side effects [1]. Lack of personal protective equipment such as masks, gowns, and gloves; lack of hospital staff due to illness; quarantine; lack of hospital and ICU beds; and social distance observing were the reasons for quotas and triage for the treatment of patients by oncologist [30]. Changes in the treatment of patients depend on the severity of the epidemic and risk factors in patients such as age over 75 years, comorbidities including hypertension, diabetes, liver failure, kidney, and lung failure [16]. The effects of COVID-19 epidemic on the treatment and follow-up of gastric cancer are summarized in Table 2.

\section{Concerns and Problems of Stomach Cancer Patients}

During the COVID-19 epidemic, many patients were concerned about the consequences of the epidemic on their treatment and follow-up. A total of $47 \%$ of patients were concerned about COVID-19 infection, which was more common among patients who were being treated or in areas with a high incidence of COVID-19 [21]. Increased sense of threat, vulnerability, and fear of COVID-19 disease have been other problems for patients [24]. Transportation and financial issues have also been a problem for patients and patients undergoing surgery; in addition to the mentioned issues, there has been a lack of social support [20]. Patients' sense of vulnerability was associated with variables such as female gender, chemotherapy, and age over 65 years. Compared to the preepidemic period, the feeling of vulnerability increased to $9 \%$ and remained stable in $42 \%$ of cases and decreased to $2 \%$. Feelings of confusion and misunderstanding, decreased feelings of pleasure, and interest of patients and increased sadness as well as discouragement have been the problems of patients during the COVID-19 epidemic [26]. The problems and concerns of patients with stomach cancer during the COVID-19 epidemic are summarized in Table 3.

Table 4 The effect of COVID-19 on the mental health of gastric cancer patients

\begin{tabular}{|c|c|c|c|c|}
\hline First author & Country & Study design/source of the data & $\begin{array}{l}\text { Quality } \\
\text { assessment }\end{array}$ & Main result \\
\hline Zhang [1] & China & A cross-sectional study & Good & $\begin{array}{l}\text { The mean anxiety score of gastric cancer patients was } \\
11.45 \pm 4.21\end{array}$ \\
\hline Miaskowski [26] & USA & Online survey & Good & $\begin{array}{l}31.6 \% \text { of patients had stress } \\
\text { Patients with stress had } 71.2 \% \text { depression, } 78 \% \text { anxiety, } \\
78 \% \text { sleep disturbance, } 91.5 \% \text { cognitive impairment, } \\
\text { and } 75.9 \% \text { had pain }\end{array}$ \\
\hline Pigozzi [25] & Italy & Prospective study & Good & $\begin{array}{l}\text { At the time of the corona epidemic, } 57 \% \text { of patients had } \\
\text { anxiety and stress, up from } 48 \% \text { before the corona } \\
\text { epidemic }\end{array}$ \\
\hline
\end{tabular}


Fig. 1 flowchart of included of study in the systematic review

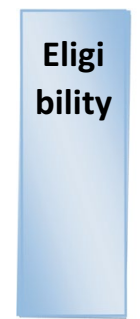

Total records identified: $\mathbf{n}=\mathbf{1 8 7}$

PubMed: 42/ web of sciences: 40 /

Scopus: 105

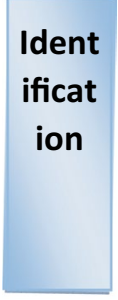

134 records included after duplicates removed
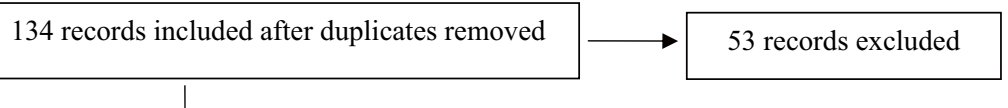

112 records excluded based on title and abstract

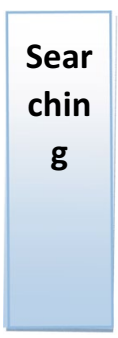

22 articles assessed for eligibility

Sear

chin
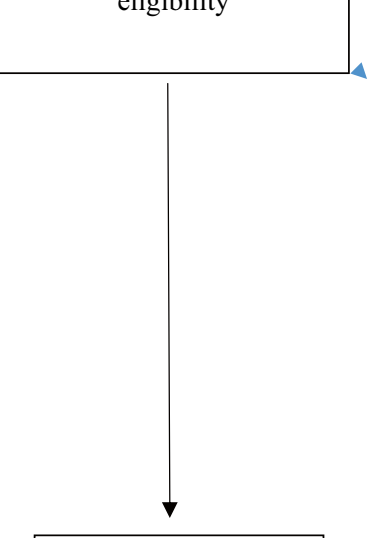

22 studies included in the synthesis
Anxiety, depression, and stress have been among the mental health problems of patients with gastric cancer. The prevalence of anxiety in resistant to treatment patients and patients with advanced cancer was higher than other patients. Also, the prevalence of anxiety was higher in patients over 60 years of age [1]. The duration of cancer diagnosis and the incidence of pain had an effect on stress [26]. Stress in gastric cancer patients increased during the corona epidemic [25] (Table 4).

\section{Discussion}

Evaluating the effects of COVID-19 on cancer will be a new priority [12]. This review article was conducted to investigate the effects of COVID-19 on gastric cancer. Reducing the diagnosis of gastric cancer was one of the negative effects of COVID-19 epidemic. Patients' fear of COVID-19 disease [11], risk of getting infection [13], and the possibility of transmission of the infection during diagnostic tests such as endoscopy, lack of strength, and personal protective equipment lead to a significant reduction in performing endoscopy and in some cases diagnostic tests are not performed or postponed. By the end of the COVID-19 epidemic, we will be aware of its effects on screening and diagnostic tests [32]. Pearson correlation test showed a linear relationship between the number of cancers diagnosed and the number of endoscopies [18]. Many patients have been referred to the emergency room for warning signs [5], indicating a delay in requesting services [2]. There will be a significant decline in endoscopic services and delays in cancer diagnosis and subsequent long-term progression of cancer. In case of $20 \%$ 
decrease in endoscopy, the average gastric cancer diagnosed per week decreases by $54.1 \%$ [18]. During the COVID-19, inappropriate endoscopic referrals decreased [19]. Although the number of endoscopies has decreased, the incidence of gastric cancer has increased significantly. In other words, the rate of gastric cancer diagnosed has increased in endoscopies [16]. The effects of the COVID-19 epidemic on gastric cancer include therapeutic changes modification, delay, or discontinuation of treatment. Many patients received advice and recommendations over the phone or video instead of at the hospital [21].

Metastasis, the patient's deteriorating nutritional status [12], upper gastrointestinal bleeding, and increased surgical complications are due to delayed treatment [11]. Lack of personal protective equipment such as masks, gowns, and gloves and hospital staff due to illness; quarantine; lack of beds; the desire to maximize social distance; and oncologists were forced to quota and triage to treat patients [30].

COVID-19 has led to more occupation of ICU beds; therefore, patients with cancers are usually not a priority for admission to the intensive care unit [33]. During this period, the performance of chemotherapy and surgery units decreased, hospital inability to provide services, transportation problems, patient perception of infection risk, financial issues, and lack of perceived social support of patients are its causes [20]. People with active cancer are one of the most at-risk groups for severe COVID-19 disease. They would not come to the hospital due to the risk of infection; therefore, there were delayed in receiving treatment [13].

Changes in cancer treatment depend on the severity of the epidemic and the presence of COVID-19, such as age over 75, blood pressure, diabetes, kidney, lung, or liver problems [22]. It affects the care of patients with cancer, and the longer the restrictions continue, the greater the impact [5]. Most patients with cancer switched from intravenous therapy to oral therapy at home [1]. Another effect of COVID-19 on gastric cancer was supplementation therapy in patients. A large number of patients seek complementary therapy, and a small number of them have shared complementary therapy with their physician or nurse [1]. A total of $71.3 \%$ of patients have started taking the supplement by their own decision [13], and most of them were not aware of its side effects [1]. Patients can be treated by performing some measures, including observing the principles of individual and collective protection in patients and staff, increasing patients' awareness of self-care behaviors, performing COVID-19 test, and taking chest radiographs before starting treatment [31].

In addition to its effects on the diagnosis and treatment of patients with gastric cancer, the COVID-19 epidemic has created some problems and concerns for patients. Many patients were concerned about the consequences of the COVID-19 on treatment, follow-up of the disease, and infection. Concern was greater in patients who were being treated or in areas with high prevalence [21]. Outpatients and surgeons have had problems with transportation, understanding the risk of COVID-19 infection, financial problems, and surgical patients have reported a lack of social support [20]. Feeling of vulnerability and fear of COVID-19 have been other problems of patients [24]. Feelings of vulnerability were associated with variables such as female gender, chemotherapy, and age over 65 years, and remained stable in 42 cases. Feelings of confusion and confusion itself, sadness and discouragement, sleep problems, lack of interest, and pleasure as well as pessimism have been other problems reported by patients [25].

Restrictions during the epidemic have had a negative impact on people's emotion psychologically and physiologically. Of course, routine follow-up and patient guidance increase patients' awareness and knowledge(13).

Anxiety in patients with cancer was higher than other patients [26]. The anxiety and stress in patients with gastric cancer during corona virus outbreak increased compared to prior to corona virus [25]. Patients' stress caused problems such as depression, sleep disorders, cognitive impairment, and a pain. Also, patients with anxiety have worse scores on resilience, social isolation, and higher overall stress and lower performance scores. The length of time a cancer has been diagnosed and the incidence of pain have affected stress so much that the less time has passed since a person was diagnosed with cancer, the more stress they will have [26].

Patients' anxiety varies according to the stage of the disease, oral chemotherapy or non-use of chemotherapy, age over 60 years, advanced incurable cancer, and knowledge of the purpose of treatment. In-person or telephone counseling can be effective in reducing patients' anxiety [1]. According to various effects of COVID-19 epidemic on diseases including gastric cancer and the continuation of the epidemic, it is essential that health officials and experts identify the effects of COVID-19 on the patients care, including gastric cancer, as well as developing and implementing interventions to minimize the negative effects of epidemics on patients.

Author Contribution Both authors contributed equally.

\section{Declarations}

Ethics Approval NA

Consent to Participate NA

Conflict of Interest The authors declare no competing interests. 


\section{References}

1. Zhang H, Yin J, Wang X, Yuan D, Zhu K, Li K. Patients' responses to the sudden interruption of chemotherapy during the outbreak of the novel coronavirus: a cross-sectional study. 2021;13:351-8.

2. Brito M, Laranjo A, Sabino J, Oliveira C, Mocanu I, Fonseca J. Digestive oncology in the COVID-19 pandemic era. GE Port J Gastroenterol.

3. Baghernezhad Hesary F, Salehiniya H, Miri M, Moodi M. Investigating preventive behaviors toward COVID-19 among Iranian people. Front Public Health 2021;9(590105).

4. Buscarini E, Benedetti A, Monica F, Pasquale L, Buttitta F, Cameletti M, et al. Changes in digestive cancer diagnosis during the SARS-CoV-2 pandemic in Italy: A nationwide survey. Curr Oncol. 2021.

5. Longcroft-Wheaton G, Tolfree N, Gangi A, Beable R, Bhandari P. Data from a large Western centre exploring the impact of COVID-19 pandemic on endoscopy services and cancer diagnosis. 2021;12(3):193-9.

6. Almasi Z, Mohammadian-Hafshejani A, Salehiniya H. Incidence, mortality, and epidemiological aspects of cancers in Iran; differences with the world data. JBUON. 2016;21(4):994-1004.

7. Zahedi A, Rafiemanesh H, Enayatrad M, Ghoncheh M, Salehiniya $H$. Incidence, Trends and epidemiology of cancers in North West of Iran. Asian Pac J Cancer Prev. 2015;16(16):7189-93.

8. Mohammadian M, Pakzad R, Towhidi F, Makhsosi M, Ahmadi A, Salehiniya $\mathrm{H}$. Incidence and mortality of kidney cancer and its relationship with HDI (Human Development Index) in the world in 2012. Public Health Clujul Medical. 2016;90(3):286-93.

9. Yusefi A, BagheriLankarani K, Bastani P, RadinManesh M, Kavosi Z. Risk factors for gastric cancer: a systematic review. Asian pac j cancer prev. 2018;19(3):591-603.

10. Alkatout I, Biebl M, Momenimovahed Z, Giovannucci E, Hadavandsiri F, Salehiniya H, et al. Has COVID-19 affected cancer screening programs? A systematic review. Front Oncol. 2021;11:675038

11. Aguayo WG, Moyon FX, Molina GA, Moyon MA, Rivadeneira DJ, Rojas CL, et al. A bleeding GIST in pandemic times, a cooperative approach to a delayed complication, a case report. Int $\mathrm{J}$ Surg Case Rep. 2020;77:880-4.

12. Cai M, Wang G, Wu Y, Wang Z, Wang G, Tao K. Study of the gastrointestinal tumor progression during the COVID-19 epidemic in Wuhan. Br J Surg. 2020;107(11):e502-3.

13. Erdem D, Karaman I. Awareness and perceptions related to COVID-19 among cancer patients: A survey in oncology department. 2020;29(6):e13309.

14. Penson D, Krishnaswami S, Jules A, Seroogy J, McPheeters M. Evaluation and treatment of cryptorchidism. comparative effectiveness review no. 88. (Prepared by the Vanderbilt Evidencebased Practice Center under Contract No. 290-2007-10065-I.) AHRQ Publication No. 13-EHC001-EF. Agency for Healthcare Research and Quality 2012.

15. De Vincentiis L, Carr RA, Mariani MP, Ferrara G. Cancer diagnostic rates during the 2020 "lockdown", due to COVID-19 pandemic, compared with the 2018-2019: An audit study from cellular pathology. J Clin Pathol. 2021;74(3):187-9.

16. Huang K, Zhao X, Chen X, Gao Y, Yu J, Wu L. Analysis of digestive endoscopic results during COVID-19. J Transl Int Med. 2021;9(1):38-42.

17. Lantinga MA, Theunissen F, Ter Borg PCJ, Bruno MJ, Ouwendijk RJT, Siersema PD. Impact of the COVID-19 pandemic on gastrointestinal endoscopy in the Netherlands: analysis of a prospective endoscopy database. Endoscopy. 2021;53(2):166-70.
18. Lui TKL, Leung K, Guo CG, Tsui VWM, Wu JT, Leung WK. Impacts of the coronavirus 2019 pandemic on gastrointestinal endoscopy volume and diagnosis of gastric and colorectal cancers: a population-based study. Gastroenterology. 2020;159(3):1164-6. e3.

19. Manes G, Saibeni S, Pellegrini L, Picascia D, Pace F, Schettino $\mathrm{M}$, et al. Improvement in appropriateness and diagnostic yield of fast-track endoscopy during the COVID-19 pandemic in Northern Italy. Endoscopy. 2021;53(2):162-5.

20. Akhtar N, Rajan S, Chakrabarti D, Kumar V, Gupta S, Misra S, et al. Continuing cancer surgery through the first six months of the COVID-19 pandemic at an academic university hospital in India: A lower-middle-income country experience. J Surg Oncol. 2021;123(5):1177-87.

21. de Joode K, Dumoulin DW, Engelen V, Bloemendal HJ, Verheij M, van Laarhoven HWM, et al. Impact of the coronavirus disease 2019 pandemic on cancer treatment: the patients' perspective. Eur J Cancer. 2020;136:132-9.

22. Takahari D, Shinozaki E, Wakatsuki T, Ooki A, Ozaka M, Suzuki $\mathrm{T}$, et al. Managing a gastrointestinal oncology practice in Japan during the COVID-19 pandemic: single institutional experience in The Cancer Institute Hospital of Japanese Foundation for Cancer Research. Int J Clin Oncol. 2021;26(2):335-44.

23. Wahed S, Chmelo J, Navidi M, Hayes N, Phillips AW, Immanuel A. Delivering esophago-gastric cancer care during the COVID-19 pandemic in the United Kingdom: a surgical perspective. Eur J Cancer Care (Engl). 2020;33(9).

24. Chia JMX, Goh ZZS, Chua ZY, Ng KYY, Ishak D, Fung SM, et al. Managing cancer in context of pandemic: A qualitative study to explore the emotional and behavioural responses of patients with cancer and their caregivers to COVID-19. BMJ Open. 2021;11(1).

25. Pigozzi E, Tregnago D, Costa L, Insolda J, Turati E, Rimondini M, et al. Psychological impact of Covid-19 pandemic on oncological patients: a survey in Northern Italy. PLoS One. 2021;16(3 March).

26. Miaskowski C, Paul SM, Snowberg K, Abbott M, Borno H, Chang S, et al. Stress and symptom burden in oncology patients during the COVID-19 pandemic. J Pain Symptom Manage. 2020;60(5):e25-34.

27. ASH Registry Offers Insights on COVID-19 in Patients with hematologic malignancies. Oncologist. 2021;26(S1):S17-S8.

28. Armellini E, Repici A, Alvisi C, Dinelli M, Gambitta P, Manes G, et al. Analysis of patients attitude to undergo urgent endoscopic procedures during COVID-19 outbreak in Italy. Dig Liver Dis. 2020;52(7):695-9.

29. Giuliani J, Bonetti A. COVID-19 and cancer: A clear change not only in daily clinical practice but also in clinical research management. J Med Virol. 2021;93(5):2564-5.

30. Bartlett DL, Howe JR, Chang G, Crago A, Hogg M, Karakousis G, et al. Management of cancer surgery cases during the COVID-19 pandemic: considerations. Ann Surg Oncol. 2020;27(6):1717-20.

31. Aznab M. Evaluation of COVID 19 infection in 279 cancer patients treated during a 90-day period in 2020 pandemic. Int $\mathrm{J}$ Clin Oncol. 2020;25(9):1581-6.

32. Gralnek IM, Hassan C, Dinis-Ribeiro M. COVID-19 and endoscopy: implications for healthcare and digestive cancer screening. Nat Rev Gastroenterol Hepatol. 2020;17(8):444-6.

33. González-Montero J, Valenzuela G, Ahumada M, Barajas O, Villanueva L. Management of cancer patients during COVID19 pandemic at developing countries. World J Clin Cases. 2020;8(16):3390-404.

Publisher's Note Springer Nature remains neutral with regard to jurisdictional claims in published maps and institutional affiliations. 